\title{
ELECTRICAL DISCHARGE MACHINING OF THE COMPOSITES- A LITERATURE REVIEW
}

\author{
K. Prasad ${ }^{1}$, A. Mahamani ${ }^{2}$, P. Salonica Sravani ${ }^{3}$, K.Mounika ${ }^{4}$ \\ ${ }^{1}$ Assistant professor, Department of Mechanical Engineering, Sree Vidyanikethan Engineering College, Andhra \\ Pradesh, India \\ ${ }^{2}$ Professor, Department of Mechanical Engineering, Sri Venkateswara College of Engineering and Technology, \\ Andhra Pradesh, India \\ ${ }^{2}$ P.G Student, Department of Mechanical Engineering, Sri Venkateswara College of Engineering and Technology, \\ Andhra Pradesh, India \\ ${ }^{2}$ Assistant professor, Department of Mechanical Engineering, Sri Venkateswara College of Engineering and \\ Technology, Andhra Pradesh, India
}

\begin{abstract}
The use of unconventional machining techniques in shaping metal matrix composites (MMCs) has generated considerable interest as the manufacturing of complicated die contours. Metal matrix composites are advanced materials having high specific strength, good wear resistance, and high thermal expansion coefficient. Electrical discharge machining is a best process to make complicated shapes on the difficult to machine materials. The current paper presents a review of the research work done in electrical discharge machining (EDM) on MMCs. The review is categorized in to two stages namely wire cut EDM on composites and EDM on composites. This literature review helps to identify the suitable process parameters and their ranges in machining of composites.
\end{abstract}

Keywords: Electric discharge machining, metal matrix composites, in-situ composites.

\section{INTRODUCTION}

Among the many unconventional processing techniques, EDM has proved itself to be one among the effective tool in shaping such difficult-to-machine materials. Electrical discharge machining is used to make dies, punches and moulds. This process is best suitable for finishing automotive, aircraft and surgerical components [1]. Current, pulse on-time, pulse off time, gap voltage, feed and flushing pressure are widely used as a machining parameter. Metal removal rate, tool wear rate, taper, radial overcut and surface roughness are considered as the important responses. This process can be employed to make complicated profiles on difficult to machine materials. Metal matrix composites (MMCs) have become increasingly important in modern industrial technology. A large number of components are made of MMCs due to their useful properties such as high strength, low weight and high wear resistance. The manufacturing technology is one of the most important factors in the successful use of cutting methods; there occurs extreme tool wear due to the abrasive nature of reinforced particles. The formation sub-surface damages such as workhardening of the matrix, delaminating between matrix and particle, and crack of particle or matrix were reported when machining MMCs at mild cutting condition. The current paper reports the electrical discharge machining of aluminum matrix composites.

\section{WIRE-CUT EDM ON COMPOSITES}

Ganpatrao et al. [2] attempted to study the determination of material removal rate of WEDM of metal matrix composites using dimensional analysis. They proposed semi-empirical model of MRR in WEDM based on thermo physical properties of the work piece and pulse-on time, average gap voltage. An empirical model based on response surface method was developed.

Ganpatrao et al. [3] conducted a study on WEDM of alumina particulate-reinforced aluminium matrix composites. The effect of combination of reinforcement, current, pulse ontime, off-time, servo reference voltage and maximum feed speed, wire speed, flushing pressure and wire tension on cutting speed, surface finish, and kerf width was determined by Taguchi orthogonal array. The optimum machining parameter combinations were obtained for surface finish, cutting speed, and kerf width separately.

Lal et al. [4] conducted an experimental study on Wire electrical discharge machining of AA7075/SiC/A12O3 hybrid composite fabricated by inert gas-assisted electromagnetic stir-casting process. The objective of the paper was to investigate the effect of WEDM process parameters like discharge duration, pulse interval time, discharge current and the wire drum speed on the kerf width while machining newly developed hybrid metal matrix composite (Al7075/7.5\% SiC/7.5\% Al2O3). The discharge 
current has most significance on kerf than discharge duration.

Rozenek [5] analysed the electrical discharge machining characteristics of metal matrix composites. They studied the influence of discharge current, pulse-on time, pulse-off time and voltage on the machining feed rate and surface roughness during WEDM of metal matrix composite $\mathrm{AlSi}{ }_{7} \mathrm{Mg} / \mathrm{SiC}$ and $\mathrm{AlSi}_{7} \mathrm{Mg} / \mathrm{Al}_{2} \mathrm{O}_{3}$. The analysis of results shows that maximum cutting speed of $\mathrm{AlSi}_{7} \mathrm{Mg} / \mathrm{SiC}$ and $\mathrm{AlSi}{ }_{7} \mathrm{Mg} / \mathrm{Al}_{2} \mathrm{O}_{3}$ composites are obtained to be approximately 3 times and 6.5 times lower than the cutting speed of aluminium alloy.

Samy et al. [6] developed a mathematical modelling for wire electrical discharge machining of Aluminium-Silicon Carbide composites. They optimized WEDM characteristics such as the MRR, cutting speed and the surface roughness was developed. The process parameters considered are the average machining voltage, the pulse frequency, the work piece height, the kerf size and the percentage volume fraction of $\mathrm{SiC}$ present in the aluminium matrix.

Satish kumar et al. [7] presented an experimental study of wire electrical discharge machining characteristics of Al6063/SiCp composites. In this work, the effect of WEDM parameters such as pulse on time, pulse off time, gap voltage and wire feed on material removal rate and surface roughness in MMCs consisting of Al6063 and SiCp are given. Regression equations are developed to predict the output parameters for A16063 and composites.

\section{DIE SINK EDM ON COMPOSITES}

Hocheng et al. [8] conducted a preliminary study of material removal in electrical-discharge machining of SiC/A1. They developed a correlation between the electrical current and on-time, and the crater size produced by a single spark for the representative material $\mathrm{SiC} / \mathrm{Al}$. They observed large size crater in $\mathrm{Al} / \mathrm{SiC}$ than steel. They recommended large current and short on time for obtaining minimal crater.

Seok et al.[9] aimed for characteristic evaluation of $\left(\mathrm{Al}_{2} \mathrm{O}_{3}\right)$ / (CNTs) hybrid composites for micro-electrical discharge machining (EDM). Catalytic chemical vapour deposition method was used to produce Alumina matrix composites reinforced with CNTs. Electrical conductivity of the materials and homogeneous distribution of CNTs in the matrix are considered as important factors for micro-EDM of A12o3/CNTs hybrid composites.

Hwa et al. [10]conducted a feasibility study of rotary electrical discharge machining with ball burnishing for $\mathrm{Al}_{2} \mathrm{O}_{3} / 6061 \mathrm{Al}$ composite. This study was conducted to find out the feasibility and optimization of a rotary EDM with ball burnishing for finding out the machinability of $\mathrm{Al}_{2} \mathrm{O}_{3} / 6061 \mathrm{Al}$ composite using the Taguchi method. Machining rate, surface roughness and improvement of surface roughness are considered for optimizing machining technique. The analysis of results supports practical technique for applying rotary EDM with ball burnishing in machining the $\mathrm{Al}_{2} \mathrm{O}_{3} / 6061 \mathrm{Al}$ composite.

Hwa et al. [11] examined wire electrical discharge machining of $\mathrm{Al}_{2} \mathrm{O}_{3} \mathrm{p} / 6061 \mathrm{Al}$ composites. They studied the effect of pulse-on time on machining performance, cutting speed, the width of slit and surface roughness. The results reveals that very low wire tension, a high flushing rate and a high wire speed are required to avoid the wire breakage in machining $\mathrm{Al}_{2} \mathrm{O}_{3} \mathrm{p} / 6061 \mathrm{Al}$ composites.

Narendara singh et al [12] investigated the electrical discharge machining of $\mathrm{Al}-10 \% \mathrm{SiC}$ metal matrix composite. They selected current, pulse on time, flushing pressure as machining parameters. The response to be studied for this study was metal removal rate, tool wear rate, radial over cut and surface roughness. They reported the effect of each machining parameter on the responses.

Karthikeyan et al [13] attempted to optimize the electrical discharge machining characteristics of $\mathrm{LM} 25 \mathrm{Al} / \mathrm{SiC}_{\mathrm{P}}$ metal matrix composites using goal programming. They developed polynomial models for EDM characteristics such as metal removal rate, tool wear and surface roughness in terms of volume fraction, current and pulse on time. They reported the each parameter on the responses.

Karthikeyan and Sornakumar [14] conducted EDM studies on LM24 Al-SiC metal matrix composites. They studied the effect of current and volume fraction of composites on surface roughness and materiel removal rate. They found that material removal rate and surface roughness are increased by increasing current.

Narender singh et al [15] attempted to optimize machining parameters in machining of $\mathrm{Al}-10 \% \mathrm{SiCp}$ composites. They employed multi response optimization method called grey relational analysis. The experimental investigation shows that the optimal setting shows that there is considerable improvement in the process.

R.K.Garg et al [16] presented a literature review of sinking EDM and WEDM on metal matrix composite materials. It was observed from their review $\mathrm{SiC}$ reinforce composites are widely reported to the literature, most of research work carried out for optimization and improvement of performance measures.

Chicosz and Karokzak [17] investigated the EDM machinability of $\mathrm{Al} / \mathrm{Si} / \mathrm{Mg}-\mathrm{Al} 2 \mathrm{O} 3$ metal matrix composites. They studied the effect of current on the surface layer formation of machined surfaces. They found that the optimized pattern of current density and frequency of sparks will improve the machining performance.

Adrian et al [18] studied the EDM characteristics of ALsi7cumg-sic metal matrix composites. They investigated the effect of tool diameter and pulse on time on tool wear and metal removal rate. They observed that increase in electrode diameter increase the metal removal rate and 
reduce the tool wear rate. Tool wear rate more when increasing the pulse on time. Whereas increase in pulse on time increase metal removal rate.

Nanimina et al [19] studied the effects of EDM on Al606130\%A12 O3 .Metal matrix composites. They selected peak current, pulse on time and pulse off time as machining parameter and material removal rate and tool wear rate as responses. They found the High current and pulse on time increase the material removal rate. More tool wears are observed at low peak current and pulse on time.

Adrian et al [20] investigated the effect of micro drilling by EDM by Al/Sic hybrid composite. They used pulse on time, pulse off time and peak current values was used as parameters of EDM Dhar et al [21] aimed to study process. They evaluated material removal rate, electrode wear rate and machined surface quality of the machined surface . They reported that is most influential factor for material removal rate and electrode wear was peak current. They also developed mathematical model for material removal rate and tool wear rate using regression analysis.

Dhar et al [21] aimed to study the effect of current, pulse on time and gap voltage on material removal rate, tool wear rate and radial over cut in electrical discharge machining of $\mathrm{Al}-$ $4 \mathrm{Cu}-6 \mathrm{Si}$ alloy reinforced with $10 \% \mathrm{SiC}$ composites. They developed mathematical model to establish relationship among the parameter.

Ahamed et al [22] studied the inclusion of $\mathrm{B}_{4} \mathrm{C}$ and glass reinforcement in the Al-SiC composites. They observed that long pulse duration to remove the reinforcements embedded in the matrix. A trade off analysis has been done between the levels of parameters to achieve combined objectives of current. The increase in reinforcement ratio decreases the material removal rate and surface cracks.

Electrical discharge machining studies on in-situ composites are very Muller and Monaghan [23] conducted a comparative experimental study of particulate reinforced aluminum matrix composites using EDM, laser beam machining, abrasive jet machining. They observed that the subsurface damage of EDM was very small when compared to other machining process.

Electrical discharge machining of in-situ composites are very limited. Prabu et al [24] conducted electrical discharge machining studies on $\mathrm{Al}^{-\mathrm{TiB}_{2}}$ with low-frequency vibrating tool. It is seen from the results, material removal rate and surface cracks of the work piece increases with an increase in current. The increase in reinforcement ratio decreases the material removal rate and surface cracks.

Senthil [25] proposed a multi criteria optimization technique to optimize the electrical discharge machining parameter in machining of $\mathrm{Al}-\mathrm{CuTiB}_{2}$ in-situ metal matrix composites. Discharge current, pulse on time and pulse off time are considered as machining parameter and material removal rate, tool wear rate and surface roughness as response parameters. The result analysis shows that, the optimized results are good agreement with confirmation run.

\section{CONCLUSIONS}

The literature review clearly indicates that the EDM and WEDM on composites are widely reported in literatures. Silicon carbide and Aluminum oxide reinforced composites widely studied in the literatures. The composites with reinforcements like TiB2 and $\mathrm{ZrB} 2$ are studied. Most of the authors are studied the micro machining behavior of ex-situ composites. Few authors are attempted to study the hybrid metal matrix composites. Most of studies focusssed either parametric investigation or optimization. However, a common observation has been made that the surface quality is achieved by compromising the material removal rate. Excessive material removal rate causes crack and re cast layer formation on the machined surface. EDM on in-situ metal matrix composites are not taking attention of many researchers. Therefore EDM studies on in-situ metal matrix composites will be our future investigation.

\section{REFERENCES}

[1]. K.H.Ho and S.T.Newman, (2003). "state of the art electrical discharge machining", International journal of machine tools and manufacture, 4310:1287-1300.

[2]. Nilesh Ganpatrao Patil and P. K. Brahmankar, (May 2010). "Determination of material removal rate in wire electro-discharge machining of metal matrix composites using dimensional analysis", The International Journal of Advanced Manufacturing Technology. Vol. 48, pp 537-555.

[3], Nilesh G. Patil and P. K. Brahmankar. (February 2014). "Some studies into wire electro-discharge machining of alumina particulate-reinforced aluminum matrix composites",Journal of the Brazilian Society of Mechanical Sciences and Engineering. Vol 36, pp 335-346.

[4], Shyam Lal, Sudhir Kumar, Z. A. Khan, and A. N. Siddiquee, (February 2014). "Wire electrical discharge machining of AA7075/SiC/A12O3 hybrid composite fabricated by inert gas-assisted electromagnetic stir-casting process", Journal of the Brazilian Society of Mechanical Sciences and Engineering. Vol 36, pp 335-346.

[5]. M. Rozenek, J. Kozak, L. Dąbrowski, K. and Łubkowski. (February 2001). "Electrical discharge machining characteristics of metal matrix composites", Journal of Materials Processing Technology. Vol 109, Pages 367-37015.

[6]. Samy Ebeid, Raouf Fahmy and Sameh Habib (2004). "Mathematical Modelling for Wire Electrical Discharge Machining of Aluminum-Silicon Carbide Composites", Proceedings of the 34th International MATADOR Conference, pp 147-152.

[7]. D. Satishkumar, M. Kanthababu, V. Vajjiravelu, R. Anburaj, N. Thirumalai Sundarrajan and H. Arul. ( December 2012). "Investigation of wire electrical discharge machining characteristics of Al6063/SiCpcomposites",The International Journal of Advanced Manufacturing Technology, Vol 63, pp 1191-1202. 
[8]. H. Hocheng, W.T. Lei and H.S. Hsu. (January 1997). "Preliminary study of material removal in electricaldischarge machining of $\mathrm{SiC} / \mathrm{Al}$, Journal of Materials Processing Technology", Pages 813-818.

[9]. Hyun-Seok Tak, Chang-Seung Ha, Ho-Jun Lee, HyungWoo Lee, Young-Keun Jeong, and Myung-Chang Kang. (January 2011). "Characteristic evaluation of Al 2O 3/CNTs hybrid materials for micro-electrical discharge machining", Transactions of Nonferrous Metals Society of China - Trans Nonferrous Metal Soc Ch; 21. DOI:10.1016/S10036326(11)61055.

[10]. Biing Hwa Yan, , Hsien Chung Tsai, Fuang Yuan Huang, and Long Chorng Lee. (March 2005). "Examination of wire electrical discharge machining of $\mathrm{Al} 2 \mathrm{O} 3 \mathrm{p} / 6061 \mathrm{Al}$ composites", International Journal of Machine Tools and Manufacture, Pages 251-259.

[11]. Biing Hwa Yan, Che Chung Wang, , Han Ming Chow and Yan Cherng Lin. (August 2000). "Feasibility study of rotary electrical discharge machining with ball burnishing for Al2O3/6061Al composite", International Journal of Machine Tools and Manufacture, Vol 40, Pages 1403-1421.

[12]. P.Narendrasingh, K.Raghukandan, M.Rathinasabapathi and B.C.Pai, (2000). "Electric discharge machining of Al$10 \% \mathrm{SiC}$ as cast metal matrix composites", Journal of material processing technology, Vol 155 -156, p.1653-1657.

[13]. R.Karthikeyan, S.Raju and R.S.Nagavazen,( 2001). "Optimization of EDM characteristics of SiC/LM $25 \mathrm{Al}$ composite using goal programming", Journal of material science technology, Vol 17, p.57-60.

[14]. M.Karthikeyan and T.Sornakumar. (2010). "EDM studies on aluminum alloy-silicon carbide composites developed by vortex technique and pressure die casting“", Journal of minerals and material characterization \& Engineering, Vol 9, p.77-88.

[15]. P.Narender Singh, K. Raghukandan and B.C. Pai. (2004). „Optimization by Grey relational analysis of EDM parameters on machining $\mathrm{Al}-10 \% \mathrm{SiCP}$ composites“, Journal of Materials ProcessingTechnology, Vol 155-156, p.16581661 .

[16]. R. K. Garg, K. K. Singh, Anish Sachdeva,Vishal S. Sharma, Kuldeep Ojha, and Sharanjit Singh. (September 2010). "Review of research work in sinking EDM and WEDM on metal matrix composite materials", The International Journal of Advanced Manufacturing Technology, Vol 50, pp 611-624.

[17]. P.Chicosz and P.Karokzak. (2008) "Sinking EDM of aluminum matrix composites", Material science-poland,vol 26,No.3, 547-554.

[18]. Adrin Iosub, Gheorghe Nagit and Florin Neogoscu, (2009). "Tool wear investigation in EDM of aluminum matrix composites", The annas of Duharea De Jos, University of galati, ISSN 1221-4566,Pg225-228.

[19]. A.Mouangue nanimina,A.M.Abdul Ran, F.Ahamd, A.Zainuddin and S.H. Jason Lo. (2010). "Effect of EDM on aluminum metal matrix composites", Journal of applied science, DOI 10-3923/jan 2011, Pg1-5.

[20]. Adrian Iosub, Gheorghe Nagit, and Florin Negoescu. (2009). "Tool wear investigation in electric discharge machining of aluminum matrix composite materials", Avilable at http://www.tcm.ugal.ro/tmb/2009/l40.pdf.
[21]. Dhar S, Purohit R, Saini N, Sharma A, and Hemanth kumar G. (2007). "Mathematical modelling of electric discharge machining of cast Al-4Cu-6Si alloy- $10 \mathrm{wt} \% \mathrm{SiCp}$ composites", J Mater Process Technol 194:24-29.

[22]. Riaz Ahamed A, Asokan P and Aravindan S (2009)."EDM of hybrid Al-SiCp-B4Cp and Al- SiCpGlassp MMCs", Int J Adv Manuf Technol 44:520-528.

[23]. F.Muller,J.Monaghan. (2000). "Non conventional machining of particle reinforced aluminum matrix composites", International journal of machine tools and manufacture, 43:1287ᄀ-1300.

[24]. M. Prabu, G. Ramadoss, P. Narendersingh, T.V. Christy and V. Vedhagiri Eswaran. (2013). "Electrical discharge machining of Al-TiB2 with low-frequency vibrating tool", Science and Engineering of Composite Materials, Vol 0, p.1-8, DOI: 10.1515/secm-2013-0023.

[25]. P.Senthil, Vinodh Sekar and Adarsh Kumar Singh. (2014). „Parametric optimization of EDM on Al- Cu/TiB2 in-situ Metal Matrix Composites using TOPSIS method“, International Journal of Machining and Machinability of Materials (Accepted manuscript),Available at http://www.inderscience.com/info/ingeneral/forthcoming.ph $\mathrm{p} ? \mathrm{j} \operatorname{code}=\mathrm{ijmmm}$,

\section{BIOGRAPHIES}

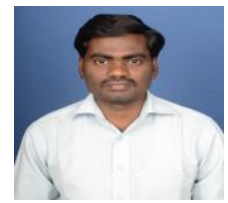

K. Prasad obtained his bachelor of Technology degree in Mechanical Engineering from Sri Venkateswara University, Tirupathi, India and Master's Degree in Advanced Manufacturing Systems with honors in Mechanical Engineering from JNTUH, Hyderabad in 2010. He is perusing his $\mathrm{PhD}$ in the area of Metal Matrix Composites. He is presently working as Assistant Professor in Mechanical Engineering department at Sree Vidyanikethan Engineering College, Tirupathi, India.

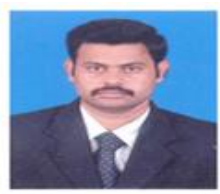

Dr.A.Mahamani completed his $\mathrm{PhD}$ in JNTU Anatapur,A.P., and Master's Degree in Annamalai University,T.N. His area of research includes Manufacturing and Composites. He published more than 70 papers in conference proceedings and Journals .He is presently working as a Professor in Mechanical Engineering department at Sri Venkateswara College of Engineering \& Technology, Chittoor.A.P.

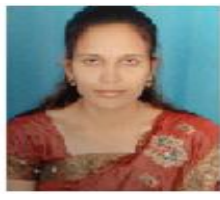

P. Salonica Sravani completed her B. Tech in Mechanical Engineering in Annamacharya Institute of Technology \& Sciences. She is pursuing her M. Tech at Sri Venkateswara College of Engineering $\&$ Technology, Chittoor, A.P. She is doing her project work on Electric Discharge Machining of In-situ metal matrix composites.

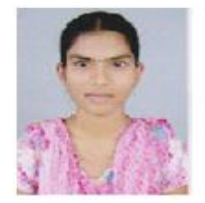

K.Mounika completed her M. Tech in Mechanical Engineering at Sri Venkateswara College of Engineering \& Technology, Chittoor, A.P. Her area of interest is composites and manufacturing. She is 
working as an Assistant professor in Sri Venkateswara

College of Engineering \& Technology. 